\title{
ORALIDADE E ESCRITA EM TEXTOS DE ALUNOS DO ENSINO FUNDAMENTAL I DE UBERABA-MG ${ }^{1}$ \\ ORALIDAD Y ESCRITA EN TEXTOS DE ALUMNOS DE LA ENSEÑANZA BÁSICA DE UBERABA-MG
}

\author{
Débora Gonçalves Samuel \\ Universidade Federal do Triângulo Mineiro (UFTM) \\ Juliana Bertucci Barbosa \\ Universidade Federal do Triângulo Mineiro (UFTM) \\ Mestrado Profissional em Letras (PROFLETRAS)
}

RESUMO: Este artigo tem por objetivo investigar os desvios ortográficos presentes na escrita de alunos do Ensino Fundamental I da cidade de UberabaMG. Para isso, elaboramos e aplicamos testes de diagnose para coleta dos dados. Após essa etapa, investigamos os desvios mais frequentes, em especial aqueles que evidenciam a transposição da oralidade para escrita.

PALAVRAS-CHAVE: Oralidade, escrita, diagnose, desvio de ortografia.

RESUMEN: Este artículo tiene por objetivo investigar las desviaciones ortográficas presentes en la escritura de alumnos de la Enseñanza Fundamental I de la ciudad de Uberaba-MG. Para ello elaboramos y aplicamos pruebas de diagnósticas para recoger los datos. Después de esa etapa, investigamos las desviaciones más frecuentes, principalmente aquellas que evidencian la transposición de la oralidad para escritura

PALAVRAS CLAVE: Oralidad, escritura, pruebas diagnósticas, desviación.

\section{Introdução ${ }^{2}$}

Estudos sociolinguísticos, como os de Naro e Scherre (1991), Mollica (1998), Bortoni-Ricardo (2005), entre outros, trouxeram contribuições relevantes para o que antes o senso comum considerava como "erro" na fala dos usuários da língua. Tais pesquisas têm evidenciado que esses "erros" cometidos pelos falantes são, na realidade, variações de uma mesma língua e que, além disso, são previsíveis e sistemáticos. Algumas dessas variações que ocorrem na modalidade falada podem, às vezes, transporem-se para a escrita, principalmente no início da escolarização.

\footnotetext{
${ }^{1}$ A pesquisa ganhou prêmio de "MELHORES TRABALHOS APRESENTADOS NA III JIEPE 2017" na UFTM-Uberaba

${ }^{2}$ Agência de Fomento: BIC FAPEMIG e CNPq.
} 
Buscando discutir essas questões, começou-se a desenvolver-se no Brasil, a partir de estudos como os de Lemle (1982) e Bortoni-Ricardo (2004 e 2005), uma sociolinguística aplicada à educação cujo foco é o exame dos vários fenômenos da variação linguística, característicos do Português Brasileiro (PB), analisados em suas implicações para o processo de ensino-aprendizagem, principalmente no Ensino Fundamental.

Essas pesquisas vêm trazendo grandes contribuições para a compreensão do funcionamento da escrita no início da escolarização e, também, mostrando o quanto é necessário o respeito ao desenvolvimento linguístico do aluno, a fim de que não se rompa a motivação e a criatividade linguística. Tais estudos apontam, também, que alguns problemas apresentados pelos alunos na fase inicial da escrita podem ser explicados por transposição de seus hábitos de fala - como, por exemplo, o apagamento do ' $r$ ' em final de verbos no infinitivo, como em comer / "come" ou a monotongação, como em caixa I "caxa" -, casos que podem ser solucionados a partir do desenvolvimento de práticas pedagógicas coerentes com a fase linguística do aprendiz.

Assim, seguindo essas reflexões, esta pesquisa tem como objetivo geral identificar e classificar os desvios ${ }^{3}$ ortográficos a partir de um corpus constituído de produções textuais escritas por alunos do Ensino Fundamental I, de 7 a 9 anos, de escolas públicas da cidade de Uberaba, analisando de que forma a oralidade pode influenciar na escrita desses alunos.

Para atingirmos nosso objetivo, neste artigo, inicialmente, apresentamos uma discussão sobre o conceito de oralidade, desvios ortográficos, ensino de língua e variação linguística. Em seguida, explicitamos as orientações metodológicas, bem como os procedimentos necessários para nortear a pesquisa. Por fim, apontamos os resultados das análises, juntamente com as considerações finais sobre os dados analisados.

\footnotetext{
${ }^{3}$ Bortoni-Ricardo (2006, p; 273) utiliza o termo "erro" para qualquer "transgressão de um código convencionado e prescrito pela ortografia" na escrita. Para a autora, "[...] podemos considerá-lo uma transgressão porque a ortografia é um código que não prevê variação" (BORTONIRICARDO, 2006, p. 273). Já autores como Tenani e Reis (2011) usam a expressão "grafia não convencional", por assumirem uma heterogeneidade na ortografia. A fim de uniformizar nossa discussão, optaremos pelos termos "desvio" e "erro", referindo-se, assim, às grafias que não correspondem à normatização ortográfica de nosso país.
} 


\subsection{Variação linguística, oralidade e escrita}

Nesta seção, apresentamos sucintamente a revisão teórica sobre os principais temas do artigo: oralidade, desvios ortográficos e a relação ensino de língua e variação linguística.

\subsection{O contexto escolar e ensino de língua materna no Brasil}

Neste artigo, defendemos a importância de se levar em consideração a presença da variação linguística no ensino de língua desde as séries iniciais como é previsto nos documentos oficiais (como veremos na subseção 2.3). Entretanto, em relação a própria diversidade sociolinguística, o Brasil ainda carece de um estudo profundo que compreenda e compute as variedades hoje existentes no nosso território. Assim as mudanças no ensino de português como língua materna que adicionaria ao conteúdo que é repassado em sala aos alunos, a importância do conhecimento e do uso adequado a um determinado contexto.

Em suas pesquisas, Bortoni-Ricardo (2005) classifica a realidade linguística brasileira diferente da que é considerada por outros estudos. $\mathrm{Na}$ sociolinguística moderna são levados em conta três tipos de realidade: "sociedades multilíngues, multidialetais e comunidades falantes de línguas crioulas ou pós-crioulas e ainda dialetos ou variedades urbanas e/ou étnicas em países industrializados onde a alfabetização é universal". Nenhum dos tipos anteriores mencionados pela autora seria adequado para descrever a realidade linguística brasileira.

Uma das variações presentes no Brasil, para Bortoni-Ricardo (2005), é variação diatópica rural x urbana. A linguista destaca ainda que a escola é a principal instituição que impõe o ensino para uso da norma culta, mas se esquece de ensinar também que existem contextos em que o uso da mesma pode causar a incompreensão do que se pretende falar, quando os interlocutores não partem do mesmo nível linguístico. Para exemplificar isso, Bortoni-Ricardo (2005) transcreve um trecho de um diálogo entre um entrevistadora e uma senhora de 71 anos de origem rural: 
E. A senhora esteve presente nas duas últimas reuniões da novena?

S. Se eu tive???

E. É.

S. Não.

E. A senhora não foi?

FS. E a senhora não foi naquela última novena, não?

S. Tive na novena, mas não tive presente.

(BORTONI-RICARDO, 1985 apud BORTONI-RICARDO, 2005, p.23)

O trecho transcrito evidencia que só uso da norma culta não foi suficiente para alcançar o objetivo da comunicação, pela fala da senhora e pelos milhares de brasileiros é que percebemos que a escola como maior instituição de ensino da norma culta não dá conta de seu papel, só o uso padrão da língua não comporta toda a necessidade dos falantes de se expressarem/comunicarem.

A questão não é falar certo ou errado, mas saber qual forma de fala utilizar, considerando as características do contexto de comunicação, ou seja, saber adequar o registro às diferentes situações comunicativas. É saber coordenar satisfatoriamente o que falar e como fazê-lo, considerando a quem e por que se diz determinada coisa. É saber, portanto, quais variedades e registros da língua oral são pertinentes em função da intenção comunicativa, do contexto e dos interlocutores a quem o texto se dirige. A questão não é de correção da forma, mas de sua adequação às circunstâncias de uso, ou seja, de utilização eficaz da linguagem: falar bem é falar adequadamente, é produzir o efeito pretendido. (BRASIL, 1997, p. 26)

A escola acaba por falhar com seu papel que é oferecer o acesso à norma culta de forma não alienadora. Deveria ofertá-la não como soberana, mas como qualquer outro funcionamento regente de uma língua e ainda mostrar o aluno a riqueza que a mesma permite se retirada dessa posição imposta socialmente.

\subsection{Sociolinguística Educacional e Ensino de Língua}

A Sociolinguística Educacional tem proporcionado pesquisas que buscam a construção de novas metodologias que auxiliem professores a desenvolver em seus alunos as habilidades necessárias à uma aprendizagem mais ampla, à expansão de sua competência comunicativa e à capacidade de desempenhar tarefas escolares cotidianas. Tais mudanças, no entanto, só 
ocorrerão, se os educadores, sobretudo os alfabetizadores, considerarem o conceito de "pedagogia culturalmente sensível" postulado por Erickson (1987 apud BORTONI-RICARDO, 2005), cujo objetivo é fazer um ajuste nos processos interacionais de sala de aula considerando sempre a cultura dos alunos. Portanto, se o professor e o aluno não compartilharem suas linguagens sem preconceito, será difícil promover um ensino produtivo, do ponto de vista do domínio das habilidades linguísticas.

Bagno (2007) também aponta para a necessidade de aplicar ao ensino a pedagogia da variação linguística e propõe que essa abordagem ocorra de forma organizada. Refletindo sobre o modo de tratar os fenômenos de variação e mudança no ensino da língua materna, o pesquisador menciona que a melhor opção seria "reconhecer que a escola é o lugar de interseção inevitável entre o saber erudito-científico e o senso comum, e que isso deve ser empregado em favor do/a estudante e da formação de sua cidadania" (BAGNO, 2007, p. 78), Nessa reflexão, o autor defende uma reeducação sociolinguística como papel do professor de Língua Portuguesa.

Para o autor, a reeducação sociolinguística só acontecerá quando, a partir daquilo que o aluno já sabe muito bem (ou seja, falar sua língua materna), o professor incentivá-lo a realizar reflexões a respeito da língua e conhecer os juízos de valor sociais (suas crenças) sobre a própria língua. $\mathrm{O}$ pesquisador propõe, destarte, que no ensino da língua materna se apresentem aos alunos as manifestações verbais por meio de suas análises, a fim de conhecer as crenças linguísticas sobre sua língua materna para manter ou transformar, quando necessário, suas atitudes linguísticas.

Faraco (2008) discorre a respeito da situação da pedagogia da variação linguística, apontando a instituição de diferentes gêneros discursivos no ensino de Língua Portuguesa como passo importante, especialmente com relação à pedagogia da leitura e da produção de texto, já que não mais se privilegia somente um tipo - o texto literário (para a leitura) ou a redação (no caso da produção de texto) -, já que é obrigação da escola oferecer tanto a experiência da literatura quanto o convívio com os textos de ampla circulação sociocultural. Entretanto, o autor ressalta que ainda estamos muito atrasados na construção de uma pedagogia da variação linguística: "Parece que não sabemos, de fato, 
o que fazer com a variação linguística na escola. E o que temos feito é seguramente bastante inadequado" (FARACO, 2008, p. 176)

\subsection{Documentos oficiais e o trabalho com a variação linguística}

Segundo Faraco (2008), os documentos oficiais de diretrizes para o ensino, já abordam a pedagogia da variação linguística, fato que o autor destaca como ganho para o ensino. Porém, como ele também destaca, mesmo com os documentos oficiais abordando essa pedagogia, ainda não se encontram presentes efetivamente nos livros didáticos trabalhos e atividades que abordem a variação linguística em sua complexidade.

Assim, reconhecida como variedade dialetal pelos Parâmetros Curriculares Nacionais - PCN (BRASIL, 1997, 1998), a variação linguística tem ganhado algum espaço nas discussões onde a pauta é o futuro e a qualidade do ensino, e dos materiais didáticos.

O domínio da língua, oral e escrita, é fundamental para a participação social efetiva, pois é por meio dela que o homem se comunica, tem acesso à informação, expressa e defende pontos de vista, partilha ou constrói visões de mundo, produz conhecimento. Por isso, ao ensiná-la, a escola tem a responsabilidade de garantir a todos os seus alunos o acesso aos saberes linguísticos, necessários para o exercício da cidadania, direito inalienável de todos. (BRASIL,1997, p. 15)

Como prevê os $\mathrm{PCN}$, é papel da escola reconhecer as diferenças e combater os mitos existentes dentro do âmbito educacional: "O problema do preconceito disseminado na sociedade em relação às falas dialetais deve ser enfrentado, na escola, como parte do objetivo educacional mais amplo de educação para o respeito à diferença" (BRASIL,1997, p. 26) o mais arraigado na nossa cultura e sociedade é o de que existe apenas uma maneira certa de falar.

A norma culta é tomada como única por ser a de maior prestígio e circular no meio das classes mais favorecidas. Ao longo da história da educação no Brasil o educador se depara com uma sala de aula mista. Devido a migração da zona rural para as cidades, como explica Bortoni-Ricardo 
(2005), é possível notar a através das variedades, uma mistura ampla da norma culta "um construto sócio histórico que serve de referência para estimular um processo de uniformização" (FARACO, 2008, p.75) pretendida, pois o real acesso desta, previsto pelo mesmo documento aqui tratado, não consegue atingir as classes menos favorecidas. Tal infortúnio se deve, muitas vezes, ao fato de questões relacionadas à variação linguística ou fonéticofonológicas, não serem do conhecimento do professor, e assim a ampla possibilidade da língua (oral) do PB passa despercebida ou é tomada por erro grave.

É preciso atentar-se às variedades de seu aluno, sempre que possível, ao seguir com os conteúdos: respeitando a oralidade trazida para sala de aula. Dessa forma, o aluno compreenderá os possíveis usos da língua oral e consequentemente fará a distinção entre fala e escrita.

[...]se poderia supor até então, que elas não entravam na escola completamente desinformadas, que possuíam um conhecimento prévio. Mas, as de famílias mais favorecidas tinham maiores oportunidades de participação em atividades sociais mediadas pela escrita, possuíam muito mais experiências significativas com a escrita do que as crianças das classes menos favorecidas, e essa diferença, que se expressava no desempenho, marcou a vida escolar dessas crianças desde o seu início." (BRASIL,1997. p. 20)

Há a necessidade de a língua ser apresentada como uma caixa de ferramentas, para cada ocasião uma ferramenta diferente. "Não se trata de ensinar a falar ou a fala "correta", mas sim as falas adequadas ao contexto de uso." (BRASIL, 1997, p. 15). Vista como um instrumento de interação social, meio em que o indivíduo interage e partilha sua noção de mundo e também seus conhecimentos, acaba sendo de suma importância o domínio de todos os saberes linguísticos, obrigatoriamente em teoria, tais saberes deveriam ser proporcionados pela escola a todos os alunos e principalmente aos com menos conhecimento/acesso, de modo que o letramento fosse para todos, diferente do que acontece.

Crianças com baixo status social são ainda mais lesadas na situação atual da educação, o acesso à norma culta é um exemplo vívido disto. Se nem ao menos o acesso a língua esse conjunto de alunos possui, que dirá 
oportunidades fora da escola, dentro da escola é perpetuado o preconceito pela falta de conhecimento, não sendo propagada de forma inalienável o conhecimento profundo da língua portuguesa brasileira a todo e qualquer aluno.

Devemos nos atentar aos problemas de ordem social que podem surgir durante processo de aprendizagem, toda a bagagem de conhecimento do aluno deve ser levada em consideração uma vez que os alunos provenientes de lares onde não há o letramento tendem ao fracasso no atual sistema de ensino. $O$ ideal seria identificar através da escrita do aluno, o real motivo que levou ao uso de determinada variante.

Cabe à escola ensinar o aluno a utilizar a linguagem oral nas diversas situações comunicativas, especialmente nas mais formais: planejamento e realização de entrevistas, debates, seminários, diálogos com autoridades, dramatizações, etc. Trata-se de propor situações didáticas nas quais as atividades façam sentido de fato, pois seria descabido "treinar" o uso mais formal da fala. (BRASIL,1997. p.27)

Se ao invés de propagar o uso exclusivo da norma culta pudéssemos fazer a sociedade no geral compreender que se trata mais de questões de poder e prestígio social o uso desta, a escola estaria com uma carga mais leve nos ombros e assim começaríamos a enxergar de verdade o aluno e respeitar as suas variedades. A escola cumpre seu papel com eficácia na propagação da tentativa do uso da norma culta e de fato, não se pode negar que é dever da escola ensinar a mesma. Entretanto, a criança imergida nessa arraigada cultura de prestígio social pelo uso da norma culta entenderá que dentro da língua existe esse único uso. A norma culta é propagada pelos professores que utilizam somente desta, presente na literatura ou na obrigatoriedade contida nas gramáticas de referências lusitanas e não das que correspondem ao uso da língua no Brasil, isso faz com que o educando perca a chance de valorizar as peculiaridades e os traços de sua variedade sem ao menos compreender que esses poderiam ser adequados à sua fala, em determinadas situações de comunicação.

\subsection{Aquisição da escrita}


Segundo Bortoni-Ricardo (2004), "por volta dos 7, 8 anos o falante nativo já internalizou as regras do sistema de sua língua" (BORTONI-RICARDO, 2004, p. 78), sendo que o sistema de organização da língua falada ocorre anteriormente ao da língua escrita. A partir dessa faixa etária, verifica-se a aquisição definitiva da escrita alfabética, tal processo acontece porque a criança já compreendeu que cada um dos caracteres da escrita corresponde a valores sonoros menores que a sílaba, e realiza sistematicamente uma análise sonora dos fonemas das palavras que vai escrever. Isto não quer dizer que todas as dificuldades tenham sido superadas: a partir desse momento a criança se defrontará com as dificuldades próprias da ortografia, mas não terá problemas da escrita no sentido de grafar as palavras.

Nesse sentido, "o domínio da ortografia é lento e requer muito contato com a modalidade escrita da língua. Dominar bem as regras de ortografia é um trabalho para toda a trajetória escolar, e quem sabe, para toda a vida do indivíduo" (BORTONI-RICARDO, 2005, p. 33). A escola tem o importante papel de ajudar o aluno a compreender a realidade linguística com suas contradições e variedades, a estrutura e o funcionamento da língua com suas variantes sociais, regionais e situacionais, ou seja, a diversidade linguística do Português Brasileiro deve ser tomada como conteúdo de ensino nas aulas de Língua Portuguesa.

A partir do momento em que a criança conhece o código escrito, ainda na fase da alfabetização, poderá apresentar as primeiras dúvidas em relação à grafia das palavras, considerando que ela toma a fala como referência para a escrita. Bortoni-Ricardo (2006) faz uma ressalva importante quanto ao processo inicial de alfabetização, pois é preciso que se desenvolva a decodificação de palavras com base em um processo fonológico. Ainda, segundo a autora, "aprender a reconhecer palavras é a principal tarefa do leitor principiante, e esse reconhecimento é mediado pela fonologia. Por meio da decodificação fonológica o aprendiz traduz sons em letras, quando lê, e faz o inverso quando escreve" (BORTONI-RICARDO, 2005, p. 10).

Quando o processo de aquisição da escrita ocorre considerando os processos fonológicos, ou seja, parte do conhecimento e do uso linguísticos dos alunos, a criança terá mais facilidade em lidar com as questões 
relacionadas à escrita de forma satisfatória. Porém esse processo, inúmeras vezes, não é entendido pela escola como algo natural: "a maioria das escolas, porém, não permite que a criança faça o seu aprendizado da escrita como fez o da fala. Ela não tem liberdade para tentar, perguntar, errar, comparar, corrigir, tudo deve ser feito 'certinho', desde o primeiro dia de aula" (CAGLIARI, 2006, p. 120)

A escrita é um exercício constante, nunca saberemos escrever tudo, em algum momento surgirá uma dúvida, em algum momento qualquer falante de uma língua pode se deparar com uma "exceção", se é assim para nós detentores de tantas palavras e com infinitas ferramentas de buscas, porque cobrar de crianças de 6 a 9 anos esse nível de conhecimento? "A conquista da escrita alfabética não garante ao aluno a possibilidade de compreender e produzir textos em linguagem escrita. Essa aprendizagem exige um trabalho pedagógico sistemático." (BRASIL, 1997, p.23)

A escrita que tanto cobramos de nossos alunos não será suficiente para os conhecimentos linguísticos sequentes tão pouco a escrita alfabética não proverá todos esses conhecimentos no futuro. Esse tipo de escrita é apenas o início da vida da criança no universo linguístico, o momento perfeito para cometer erros e construir uma base sólida.

Junto das regras, seria produtivo ensinar aos alunos que eles já dominam a língua que praticamente nasceram falando, agora eles precisam estar abertos a aprenderem o domínio das regras e às várias possibilidades do uso de sua língua materna. Segundo Cagliari (2006) além da importância das regras, a diferença que se faz presente na enunciação, é o que permite que as línguas existam.

Então, tendo como papel principal, a escola deveria considerar, valorizar e principalmente reconhecer o uso da variedade linguística de seu aluno. "A questão não é falar certo ou errado, mas saber qual forma de fala utilizar (e em que contexto utilizar), considerando as características do contexto de comunicação, ou seja, saber adequar o registro às diferentes situações comunicativas. É saber coordenar satisfatoriamente o que falar e como fazê-lo, considerando a quem e por que se diz determinada coisa." (BRASIL, 1997. p.21) 
A escrita é apenas uma forma de uso da linguagem que também permite informalidades.

Em seus estudos [...]os resultados dessas investigações também permitiram compreender que a alfabetização não é um processo baseado em perceber e memorizar, e, para aprender a ler e a escrever, o aluno precisa construir um conhecimento de natureza conceitual: ele precisa compreender não só o que a escrita representa, mas também de que forma ela representa graficamente a linguagem." (BRASIL, 1997. p.15)

Segundo Cagliari (2006), o objetivo da escrita é a leitura, devido ao grande número de variedades existentes no nosso país, as palavras podiam ser grafadas de diversas maneiras, principalmente seguindo a fala, o que de início não causou muitos problemas.

Entretanto, depois de tornar-se recorrente o uso e o ato de leitura, não se trataria apenas da decodificação fonética, o leitor passa exercer a leitura de acordo com a sua necessidade. Se a leitura for um poema o exercício se fará de acordo com as características necessárias para que se leia um poema, se for uma roda de leitura com crianças a mesma deve ser realizada de modo que as crianças entendam a mensagem que está sendo passada. Esse tipo de leitura tem como objetivo o entretenimento e o aprendizado das crianças. $O$ leitor é quem assume o comando, a forma de ler não é fixa. Por trás das palavras existe um significado, através da leitura alcançamos o sentido, ao ler, o que se espera como resultado não é a "variedade adequada", no momento de enunciar essa questão é irrelevante.

O objetivo desta pesquisa foi mostrar inicialmente, a fase da aquisição de escrita, as crianças vão desviar-se do sistema de escrita que lhes é imposto, esses desvios como mostraremos na análise a seguir, foram motivados por uma variedade de sua fala, uma vez que o aluno compreende como a escrita funciona, ou seja o sistema ortográfico que ela usa, a longa caminhada pelo mundo da escrita se torna mais prazerosa. É fundamental que o professor também seja conhecedor da motivação desses desvios, assim ele será capaz de mudar suas estratégias; ou como sugerem Massini-Cagliari e Cagliari (1999, p.114), é possível que o professor junto com seus alunos crie hipóteses de escrita ou dicionários onde eles possam consultar. 
Desse modo, pode-se mostrar que a variação pode ocorrer, mas que o nosso sistema ortográfico exige seguir as regas, para isso é necessário que os alunos as conheçam. Ainda segundo a autora os desvios podem ser advindos da ordem da categorização gráfica ${ }^{4}$, ao trabalhar somente uma possibilidade de design gráfico os alunos são prejudicados ao passo que não é possível reconhecer a letra " $A$ " somente nesse rótulo, é preciso apresentar aos alunos as variadas possibilidades gráficas correspondentes a esta letra e as demais. Este assunto é pertinente nesta pesquisa pois futuramente visamos ampliar o olhar para as possíveis práticas pedagógicas (nas séries em que foram aplicados os testes) que podem auxiliar o professor nessa etapa, pois em alguns dados não foi possível encontrar motivações fonológicas

\subsection{Natureza dos desvios de ortografia, oralidade e escrita}

As discussões sobre noção de erro na fala parecem superadas por parte dos estudiosos de língua. Por influência dos estudos da Sociolinguística, o "erro" passou a ser concebido como uso de uma variedade linguística. Sendo que alguns são vistos como menos salientes, pois se tornaram regra na modalidade falada, passando, assim, muitas vezes, despercebidos nessa modalidade de uso da língua (BORTONI- RICARDO; 2005).

No entanto, podemos nos questionar: como trabalhar com a noção de erro na escrita? Haja vista que a modalidade escrita é mais padronizada, ou seja, existem regras para a ortografia e, historicamente, a gramática normativa tradicional sempre foi valorizada no sistema educacional brasileiro. ScliarCabral (2003) já chama a atenção sobre as diferenças a modalidade oral e a modalidade escrita, enfatizando que enquanto a modalidade oral se desenvolve espontaneamente, a escrita é uma invenção, cuja aprendizagem intensiva e sistemática é necessária, em grande parte dos casos.

Simões (2006) nos lembra que a criança, ao entrar em contato com a escrita da língua portuguesa, necessita associar som, distintividade e representação gráfica, visto que, em nossa língua, nem todas as letras representam apenas um som, como nos casos das correspondências

\footnotetext{
${ }^{4}$ Aspecto gráfico de uma letra, relacionado ao design (cf. MASSINI-CAGLIARI; CAGLIARI, 1999. p.35)
} 
biunívocas ('p', 'b', 't', 'd', 'f', 'v'). Dessa forma, o sistema alfabético-ortográfico torna-se bastante complexo constituindo-se em uma grande dificuldade para os indivíduos, em fase de alfabetização, grafarem seus primeiros textos escritos.

Vários estudos, como os de Lemle (1982), Faraco (1992), Cagliari (2006), Bortoni-Ricardo (2005), entre outros, têm refletido sobre a ortografia e sua aquisição, trazendo propostas não só para a análise e classificação dos desvios ortográficos como também propostas metodológicas que visam a recorrer às regularidades existentes no sistema, como forma de facilitar a compreensão daqueles que estão aprendendo.

Acreditamos que os professores de Língua Portuguesa devem distinguir os chamados "erros" da modalidade oral e os "erros" identificados na modalidade escrita. Na modalidade oral, portanto, o indivíduo tem a variação a seu dispor, cabendo-Ihe aprender na escola e na vida a ajustar a variante adequada a cada contexto de uso. Já na língua escrita o erro não pode ser visto com o mesmo enfoque, tendo em vista que, quando os erros ortográficos aparecem na escrita do aluno demonstram que ele está refletindo sobre as possibilidades da língua escrita usando como base o conhecimento da língua oral.

Alguns erros na escrita são mais comuns na fase de aquisição da língua escrita, dentre eles, destacam-se: uso indevido de letra, hipercorreção, modificação da estrutura segmental das palavras (troca de letras) supressão e acréscimo de letra, juntura intervocabular e segmentação, formas morfológicas diferentes, formas estranhas de traçar a letra, uso indevido de letras maiúsculas e minúsculas, acentos gráficos, sinais de pontuação e problemas sintáticos (CAGLIARI, 2006). Se os erros de escrita têm origem no processo de alfabetização, é preciso considerar, além das práticas metodológicas que envolvem a aquisição da escrita, a homogeneidade da Língua Portuguesa e a falta de conhecimentos específicos, relacionados a fonética e a fonologia, por parte dos alfabetizadores

\section{Procedimentos Metodológicos e Montagem de Corpus}

Primeiramente, fizemos uma revisão bibliográfica sobre 0 assunto abordado neste artigo, principalmente os de enfoque variacionista e que 
envolviam o ensino de língua materna. Em seguida, montamos um corpus composto por atividades de escrita que foram realizadas por alunos de Ensino Fundamental I, de 07 a 09 anos, de diferentes escolas de Uberaba.

Para coleta das atividades escritas, desenvolvemos ${ }^{5}$, com base em Leão (2015), um teste diagnóstico de desvios de ortografia composto de três partes: uma com questões que envolvem imagens e palavras isoladas (atividades $1 \mathrm{e}$ 3), uma com palavras dentro de sentenças (atividade 2), e outra com uma proposta que envolve imagens e produção textual (atividade 4). Utilizamos também como referência, para elaboração do teste, os trabalhos de BortoniRicardo (2005) e Cagliari (2006). Segundo Bortoni-Ricardo (2005, p.53), essa "técnica da diagnose permite a identificação dos erros, bem como a elaboração de materiais didáticos destinados a atender as áreas cruciais de incidência". Cagliari (2006) também faz referência aos desvios afirmando ser indispensável que o professor faça um levantamento dos desvios e dificuldades de seus alunos. Segundo o autor, "todo o professor deveria realizar essa diagnose dos erros de seus alunos pelo menos uma vez, para poder realizar um trabalho mais direcionado em sala de aula" (CAGLIARI,2006, p. 146)

Cabe mencionar que só analisamos atividades de alunos cujos responsáveis legais autorizaram a sua participação neste projeto ${ }^{6}$, assinando o termo TCLE. De posse desse material, as atividades desenvolvidas pelos alunos foram transcritas e, posteriormente, foram selecionadas as inadequações de escrita - os considerados erros graves, segundo a gramática normativa. Esses desvios foram classificados e investigados, quantitativa e qualitativamente, adaptando os pressupostos enumerados por Bortoni-Ricardo (2005, p. 54-58):

\section{Tipo 1 - desvios decorrentes da própria natureza arbitrária do sistema de} convenções da escrita: neste tipo se encaixam os que resultam do conhecimento insuficiente das convenções que regem a língua escrita,

${ }^{5}$ O teste foi desenvolvido durante a pesquisa de iniciação cientifica intitulada MARCAS DE ORALIDADE EM TEXTOS ESCRITOS POR ALUNOS DO ENSINO FUNDAMENTAL I DA CIDADE DE UBERABA-MG, no período de março de 2016 a fevereiro de 2017, com apoio da agência de fomento BIC-FAPEMIG. 
provocados pelas relações plurívocas entre fonema e letra, pelo uso de diacríticos e certas peculiaridades morfológicas, como a diferença ortográfica do sufixo número-pessoal de terceira pessoa do plural: ão/am e por inadequações de acentuação gráfica. Exemplo: "profesora", "prasa” etc..

Tipo 2 - desvios decorrentes da transposição dos hábitos da fala para a escrita: desvios de natureza fonética-fonológica: trata-se da transposição de hábitos da fala para a escrita e estão divididos por meio de dois campos da fonologia: as regras fonológicas categóricas e as regras fonológicas variáveis. As primeiras ocorrem independente do meio sociodemográfico identificando o falante. As regras variáveis podem aplicar- se ou não dependendo de fatores estruturais linguísticos ou extralinguísticos. Exemplo: "pexe", cuzinha", etc

Tipo 3 - casos que não se encaixam nos grupos anteriores e refletem problemas de conhecimento da organização da língua: nesses casos, também observamos que os alunos não pronunciam as palavras conforme a palavra que escreviam ou que os desvios eram provenientes de outras questões, a partir deste fato decidimos criar uma categoria em que os desvios deste pesquisa pudesse se encaixar. Exemplo: "Quagachova”; "conpitado"

Por fim, dentre as ocorrências do Tipo 2, buscamos identificar quais os processos fonético-fonológicos, transpostos da fala para escrita, são precursores de tais desvios de ortografia.

\section{Análise fonológica dos dados de dados}

Como já mencionado, para o desenvolvimento do trabalho, elaboramos um teste diagnóstico que levasse em consideração a idade e o período de escolaridade desses alunos. O teste diagnóstico teve três partes: uma com questões que envolvem imagens e palavras isoladas (atividades 1 e 3), uma com palavras dentro de sentenças (atividade 2), e outra com uma proposta de 
produção de textual a partir das imagens (atividade 4). Assim ${ }^{7}$, a seguir, apresentamos os dados gerais:

\begin{tabular}{|c|c|c|c|}
\hline & Ocorrências & Ocorrências & Ocorrências \\
\hline & Ativ. 1 e 3 & Atividade 2 & Atividade 4 \\
\hline $\begin{array}{c}\text { Tipo I } \\
\text { Desvios decorrentes } \\
\text { da própria natureza } \\
\text { arbitrária do sistema } \\
\text { de convenções da } \\
\text { escrita) }\end{array}$ & $\begin{array}{c}54 \\
\text { correspondente } \\
\text { a } 38 \% \text { dos } \\
\text { casos }\end{array}$ & $\begin{array}{l}48 \text { sentenças } \\
\text { com desvio } \\
\text { correspondente } \\
\text { a } 44 \% \text { dos } \\
\text { casos }\end{array}$ & $\begin{array}{l}13 \text { sentenças com desvios } \\
\text { correspondente a } 28 \% \text { dos } \\
\text { casos }\end{array}$ \\
\hline $\begin{array}{c}\text { Tipo II } \\
\text { (Desvios } \\
\text { decorrentes da } \\
\text { transposição dos } \\
\text { hábitos da fala para } \\
\text { a escrita) }\end{array}$ & $\begin{array}{c}56 \\
\text { correspondente } \\
\text { a } 40 \% \text { dos } \\
\text { casos }\end{array}$ & $\begin{array}{c}46 \text { sentenças } \\
\text { com desvios } \\
\text { correspondente } \\
\text { a } 42 \% \text { dos } \\
\text { casos }\end{array}$ & $\begin{array}{l}24 \text { sentenças com desvios } \\
\text { correspondente a } 51 \% \text { dos } \\
\text { casos }\end{array}$ \\
\hline Tipo III & $\begin{array}{l}31 \\
\text { correspondente } \\
\text { a } 22 \% \text { dos } \\
\text { casos }\end{array}$ & $\begin{array}{l}15 \text { sentenças } \\
\text { com desvios } \\
\text { correspondente } \\
\text { a } 14 \% \text { dos } \\
\text { casos }\end{array}$ & $\begin{array}{l}10 \text { sentenças com desvios } \\
\text { correspondente a } 21 \% \text { dos casos }\end{array}$ \\
\hline Total geral & 141 desvios & $\begin{array}{l}109 \text { sentenças } \\
\text { com desvios }\end{array}$ & 47 sentenças com desvios \\
\hline
\end{tabular}

Como podemos observar na Tabela I, os alunos do Ensino Fundamental I que participaram da nossa pesquisa, apresentam desvios de ortografia tanto decorrentes da transposição dos hábitos da fala para a escrita, ou seja, desvios de natureza fonética-fonológica (tipo 2) como decorrentes da própria natureza arbitrária do sistema de convenções da escrita (tipo 1). Além disso, em todas as atividades apresentaram alguns casos de desvios que não se encaixam nos tipos 1 e 2.

Em relação aos desvios do tipo 1, encontramos letras que foram trocadas com maior frequência, isto é, devido ao sistema ortográfico ser "arbitrário" para as crianças ao passo que possui, por exemplo, várias possibilidades para grafar um único som que é o caso das letras "S; SS; SC; Ç; C e Z," ou "Ch e X", esse sistema convencional pode não fazer sentido para as crianças que se baseiam

\footnotetext{
${ }^{7}$ Apresentaremos, neste artigo, por uma questão de delimitação, apenas os casos de desvios mais recorrentes. $\mathrm{O}$ corpus encontra-se no apêndice I.
} 
em sua fala para a produção escrita, sendo assim as crianças começam a usar sua própria lógica, que foge da convencionalidade de nosso sistema, elas começam criar suas hipóteses como nos casos de: "prasinha" "profesora" "caza" "caxorro" "cacha.

Posteriormente, dentre as palavras do Tipo 2, identificamos quais os processos fonético-fonológicos são os precursores dos desvios ortográficos encontrados. Vejamos os processos fonético-fonológico mais frequentes na atividade 2:

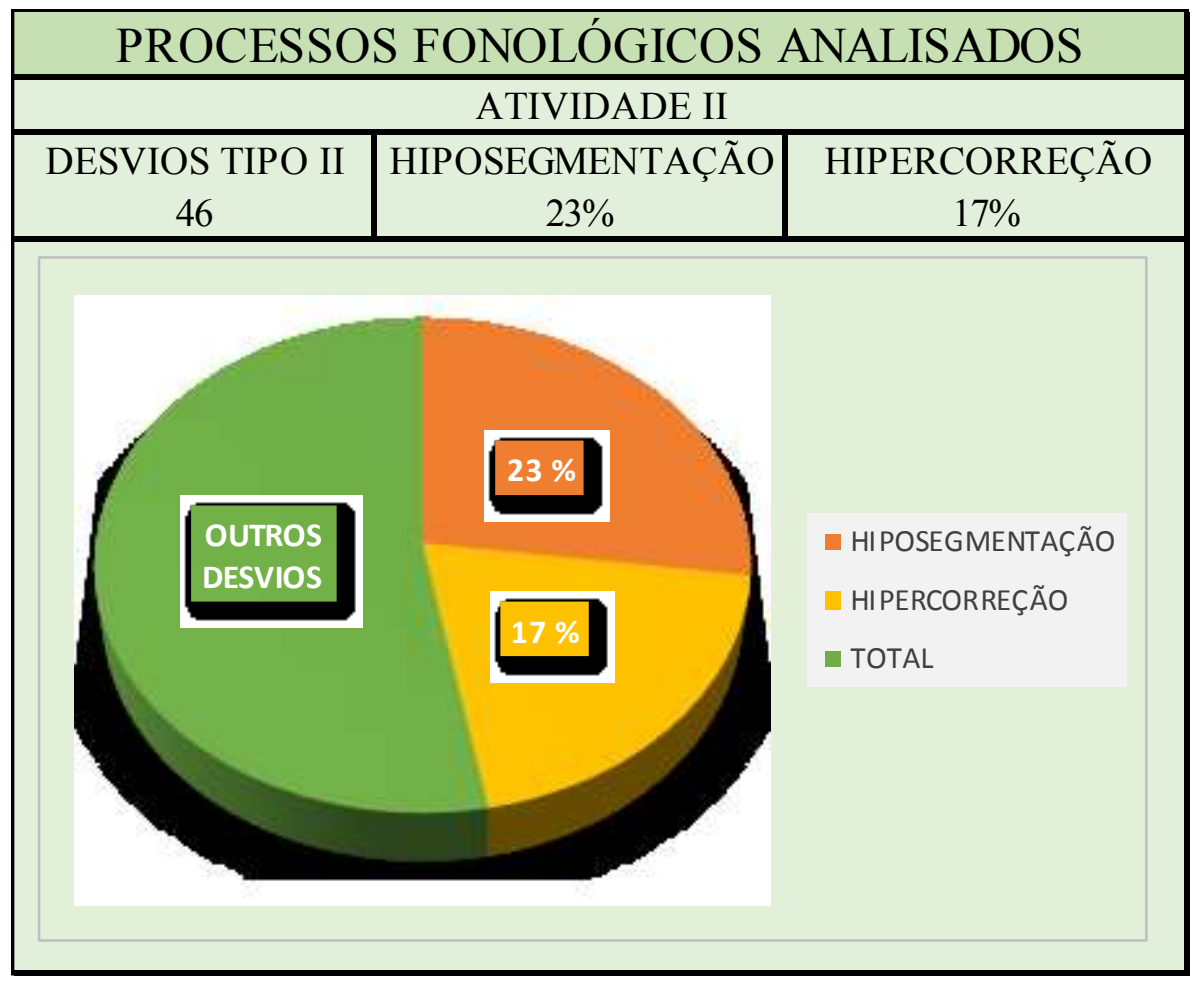

Gráfico I: processos fonético-fonológicos vs. atividade 2 Fonte: as autoras

$\mathrm{Na}$ atividade 2, foi pedido aos alunos que escrevessem sentenças, nessas estruturas o processo mais frequente foi o da hipossegmentação. Esse fenômeno também é conhecido como juntura e ocorre quando as crianças juntam as palavras ao escrever, e criam uma emenda de palavras como por exemplo "Ataçaquebrol". Em sua lógica, essa emenda representa a sentença pedida, seguindo a lógica das crianças, é aceitável que compreendamos a sentença desta maneira visto que quando falamos é o que ocorre. A segmentação das palavras não é marcada concretamente na fala como 
acontece na escrita (com os espaços em brancos entre as palavras), ainda sim a segmentação na fala é regida pela prosódia e a sua marcação pode ser diversificada. As junções que geralmente ocorrem com maior frequência no ato da escrita, segundo Pereira (2016), e conforme aparece nos dados desta pesquisa, são as junções dos artigos (palavra gramatical) à palavra de conteúdo, mas essa junção ainda pode ocorrer entre a palavra gramatical e a palavra fonológica.

Segundo Cunha e Miranda (2007), entende-se por palavra gramatical aquela que não possui sentido lexical como os clíticos e os artigos, na pesquisa consta os seguintes dados e seus processos respectivos.

As palavras mais recorrentes com caso de hipossegmentação foram:

\begin{tabular}{|c|c|c|}
\hline $\begin{array}{c}\text { Sentença } \\
\text { Sugerida }\end{array}$ & $\begin{array}{c}\text { Desvios dos } \\
\text { alunos }\end{array}$ & Processo fonológico \\
\hline $\begin{array}{c}\text { A taça } \\
\text { quebrou }\end{array}$ & Atasa que brol & $\begin{array}{c}\text { Hipersegmentação } \\
\text { Hipossegmentação Hipercorreção }\end{array}$ \\
\cline { 2 - 2 } & Atasaqebrou & Hipossegmentação \\
\hline $\begin{array}{c}\text { O gelo } \\
\text { derreteu }\end{array}$ & Ogelo derete & Hipossegmentação \\
\hline $\begin{array}{c}\text { A onça é } \\
\text { feroz }\end{array}$ & Aonsa é feros & \\
\hline
\end{tabular}

Quadro I: Dados referentes a atividade 2

Fonte: as autoras

Além da hipossegmentação, ainda encontramos "quebrol", em que há também a hipercorreção, e o aluno grafa com a letra "I" o que deveria ser grafado com a letra "u", assim como ocorre em "anel”, "pastel", etc. A juntura que se mostrou recorrente nos dados foi a junção do artigo e da palavra de conteúdo como no exemplo "Atasa quebrol" neste exemplo o artigo "a" está junto do substantivo "taça" grafado com a letra "S" como já explanamos anteriormente uma das sibilantes que foi constantemente trocadas.

Além dos casos de hipossegmentação nessa atividade pudemos notar alguns casos de hipersementação, que é o processo inverso da hipossegmentação. Nesses casos, a criança separa a palavra gramatical baseando-se na sua fala e, provavelmente, em uma pausa que a professora fez 
ao ditar as palavras. Dessa forma, a criança transcreve o que ocorre como no exemplo: "A tasa que brol" "O gelo de rete".

Vejamos agora os processos que se destacaram na atividade 1:

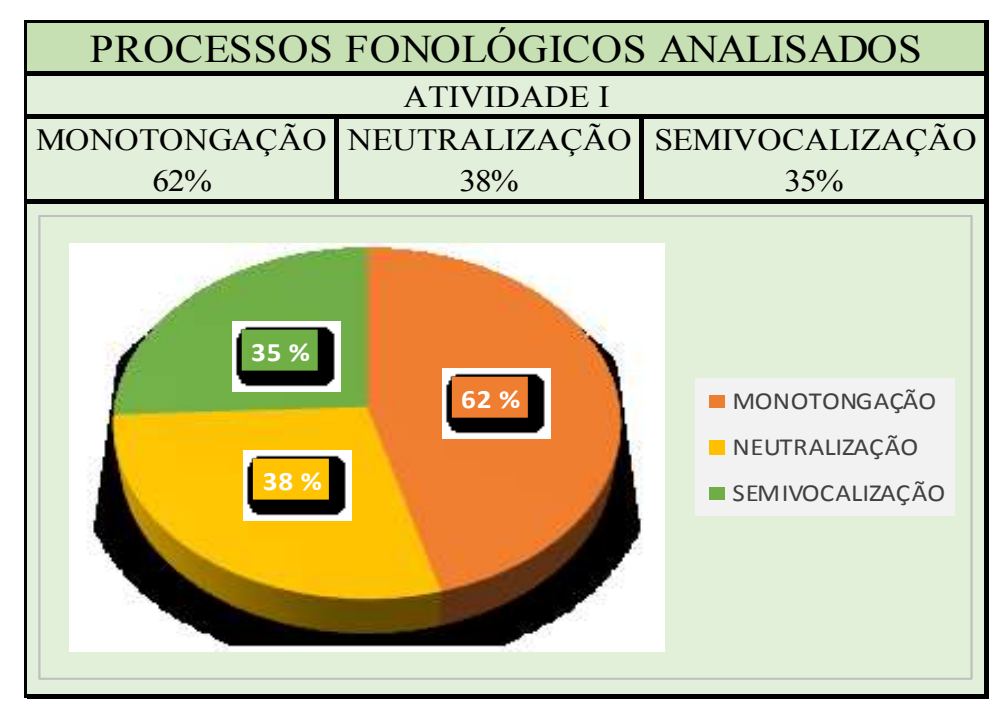

Gráfico II: processos fonético-fonológicos vs. atividade 1

Fonte: as autoras

$\mathrm{Na}$ atividade 1, em que as crianças trabalharam com palavras isoladas, verificamos que alguns dos desvios de ortografia dos alunos identificados em nosso teste podem ser motivados por processos fonológicos presentes na variedade do aluno e representados através da escrita. Resultados semelhantes ocorreram com a atividade 2. Isso acontece, principalmente, em palavras como: árvore, professora, tesoura, anel, sol, peixe e caixa. 


\begin{tabular}{|c|c|c|}
\hline Palavra & $\begin{array}{c}\text { Desvio dos } \\
\text { alunos }\end{array}$ & $\begin{array}{c}\text { Processo fonológico } \\
\text { envolvido }\end{array}$ \\
\hline Árvore & Arvori & $\begin{array}{c}\text { Neutralização das vogais } \\
\text { anteriores }\end{array}$ \\
\hline Tesoura & Tizora & $\begin{array}{c}\text { Neutralização das vogais } \\
\text { anteriores }\end{array}$ \\
\hline Anel & Aneu & \multirow{2}{*}{$\begin{array}{c}\text { Semivocalização / } \\
\text { hipercorreção }\end{array}$} \\
\cline { 2 - 2 } & Aneo & \\
\hline Sol & Sou & \multirow{2}{*}{ Monotongação } \\
\cline { 2 - 2 } & soo & \\
\hline Peixe & Pexe & \\
\hline Caixa & Caxa & \\
\hline
\end{tabular}

Quadro II: casos encontrados na atividade 2 Fonte: as autoras

Na palavra "anel", por exemplo, algumas crianças grafaram o final desta palavra da forma que pronunciam em seu dia-a-dia, ou seja, com [w] e não com a pronúncia lateralizada do /// pós vocálico. Dessa forma, foi recorrente "aneu" (alguns também grafaram "aneo", neste caso também houve hipercorreção). Como podemos observar, tal desvio é motivado pela semivocalização da consoante (neste caso, realização da consoante líquida [l] como [w]) que ocorre em alguns falares do PB, segundo Silva (2015, p.162).

Além disso, ainda na atividade 1 , ao analisar os dados, notamos que os informantes ao grafarem a palavra "tesoura", escreveram "tisora"/"tizora". Na primeira sílaba dessa palavra, na fala, em algumas variedade do português, ocorre a neutralização das vogais anteriores ${ }^{8}$, perca de contraste em ambiente fonêmico específico, a influência desse hábito da fala, levou alguns dos informantes a grafaram a palavra tesoura com t e i. Fologicamente o /t/ é pronunciado como o alofone [p] em ambiente fonológico específico, quando antecede a vogal alta [i], como em "tisora" "tizora". Houve ainda o caso "tizola", em que identificamos a representação da posteriorização ou seja, substituição da fricativa alveolar "s" por uma alveolopalatal.

\footnotetext{
${ }^{8}$ Os processos fonológicos desonorização, neutralização e posteriorização foram classificados de acordo com Othero (2005) que se baseia no aporte teórico de Stampe (1973)
} 
A monotongação, processo fonológico motivado pela fala também apareceu em várias palavras, na palavra "tizola" também aparece a monotongação de [ow] > [o]; esse fenômeno segundo (Seara, 2011 p. 43), consiste na passagem de ditongo para uma vogal com "tesora" [tfi.so,ra ], pexe> ['pe.JI] e caxa> ['ka.fa].

Ainda segundo a autora em algumas palavras, os ditongos [ei] e [aj] ei > [ej] e ai> [aj] quando em um ambiente específico são apagados, como na ocorrência relatada diante de [], sendo assim temos: pexe> ['pe.JI] e caxa> ['ka.ja].

Já na palavra "arvori" > ['aı.vo.ri], um outro hábito da fala que influenciou a escrita dos alunos foi o processo de desonorização da obstruinte. Tal processo consiste na produção das plosivas, fricativas ou africadas surdas como em arsori ['as. so.ri].

Por fim, na atividade 4, diferentemente das anteriores, as crianças deveriam produzir um texto de acordo com duas imagens. Trata-se de uma análise interessante, pois os mesmos processos fonológicos encontrados em palavras escritas isoladas foram encontrados na produção de sentenças. No entanto, um processo fonológico se destacou nessa atividade, foi o da hipossegmentação. Como explanado anteriormente, trata-se da junção das palavras, dentre todos os processos recorrentes, este foi o de maior destaque ao longo da produção textual. Entre 47 sentenças com desvios foram classificados (24) $51 \%$ no tipo II, desses $51 \%$ toda a produção textual apresentava a representação da fala na escrita.

Podemos inferir que a maioria das crianças não consegue identificar a segmentação das palavras. O que poderia ser trabalhado com as crianças seria a prosódia, uma vez que a criança conseguisse separar a fala da escrita a produção textual escrita faria mais sentido a ela. Segundo Cagliari,

as pausas da fala nem sempre têm correspondência fixa com as pausas ou sinais de pausas (vírgulas, pontos) da escrita. A segmentação das palavras na escrita, indicada pelo espaço em branco, corresponde menos ainda a pausas ou segmentações na fala. (CAGLIARI, 2006, p. 127) 
Em relação às ocorrências do Tipo 3, foram casos que identificamos que as crianças não pronunciam as palavras conforme a escreviam, por isso, não se encaixavam no Tipo 2 (não eram transposição da fala para escrita) e também não consistiam em troca da relação letra/som (tipo 1). Como, por exemplo, a palavra grafada pelo aluno: O "bãoero e bco". Portanto, temos essas situações que não se encaixam nos Tipos 1 e 2, e merecem uma análise mais minuciosa, o que não será feito neste artigo, por fugir do nosso objetivo principal.

Esse último tipo, uma das nossas hipóteses para os desvios de ortografia, é que não são somente motivados por uma questão fonética, mas também podem estar intimamente ligados a problemas em que a criança não sabe grafar a letras que determinado som representa. É importante lembrar que o nosso sistema de escrita é o fonográfico de base alfabético-ortográfico, ou seja, primeiramente as crianças precisam aprender como desenhar essas letras, se algo falha nesse processo a criança enfrentará muitos problemas ao longo da vida estudantil.

\section{Considerações finais}

Ao analisarmos os desvios de ortografia dos alunos do Ensino Fundamental I, de 07 a 09 anos, de Uberaba, verificamos que na transposição da fala para escrita (desvios do tipo 2), os processos fonético-fonológicos mais recorrentes são o da hipo e hipersementação. Cabe mencionar que além de descrever e analisar os desvios ortográficos influenciados pela oralidade, este trabalho também reflete sobre a importância de uma metodologia centrada nas necessidades do aluno no que se refere ao uso da escrita. Assim, de certa forma, buscamos também contribuir com o ensino de língua materna, destacando a responsabilidade da escola, que é preparar esse aluno para as exigências sociais e, ao mesmo tempo, respeitar a língua do seu meio.

Para isso, é necessário que se desenvolva, como diz Bortoni-Ricardo (2005), uma "pedagogia culturalmente sensível", que esteja atenta às diferenças entre a cultura dos alunos e a da escola. Há necessidade, seguindo a reflexão da autora, de encontrarmos formas efetivas de conscientizar os educandos (e os professores) sobre essas diferenças, tendo em vista a importância de se valorizar e compreender as características das variedades 
linguísticas, tanto a que a escola quer ensinar, como as pertencentes ao cotidiano do aluno. Quando chega à escola, a criança, naturalmente, já é uma usuária competente de sua língua. Entretanto, é inegável o papel da instituição, de levar os educandos a ampliarem seus recursos comunicativos a fim de que possam ter um bom desempenho nas diferentes tarefas linguísticas que lhes forem solicitadas.

\section{Referências}

BAGNO, M. Nada na língua é por acaso: por uma pedagogia da variação lingüística. São Paulo: Parábola, 2007.

BORTONI-RICARDO, S. M. Educação em língua materna: A sociolinguística na sala de aula. São Paulo: Parábola Editorial, 2004.

BORTONI-RICARDO, S. M. Nós cheguemu na escola, e agora?: sociolinguística \& educação. São Paulo: Parábola, 2005.

CAGLIARI, L.C. Alfabetização e Linguística. $10^{a}$ ed. São Paulo: Scipione, 2006.

CUNHA, A. P. N.; MIRANDA, A. R. Moresco. A influência da hierarquia prosódica em hipossegmentações da escrita de crianças de séries iniciais. Revista Virtual de Estudos da Linguagem - ReVEL. Edição especial n. 1, 2007. ISSN 1678-8931

FARACO, C. A. Norma culta brasileira: desatando alguns nós. Parábola, 2008.

FRANCHI, E. A redação na escola: e as crianças eram difíceis. São Paulo: Martins, 1990.

GUIMARÃES, M. R. Um estudo sobre a aquisição da ortografia nas séries iniciais. 2005. Tese de Doutorado. Tese (Mestrado em Educação), Faculdade de Educação da Universidade Católica de Pelotas, Pelotas.

$\mathrm{KOCH}$, I. V. Interferências da oralidade na aquisição da escrita. Trabalhos em Linguística Aplicada, Campinas, SP, v. 30, p.31-38, jul./dez, 1997.

LEMLE, M. Guia Teórico do Alfabetizador. São Paulo: Ática, 1982.

MASSINI-CAGLIARI, G; CAGLIARI, L. C. Diante das letras: a escrita na alfabetização. Campinas, SP: Mercado das Letras: Associação de Leitura do Brasil. ALB; São Paulo: Fapesp, 1999.

MOLLICA, M. C. Influência da fala na alfabetização. Rio de Janeiro, Tempo Brasileiro, 1998. 
NARO, A. J.; SCHERRE, M. M. P. Variação e Mudança Lingüística: fluxos e contrafluxos na comunidade de fala. In: Cadernos Estudos Lingüísticos. Campinas (20): 9-16, Jan/Jun. 1991.

OTHERO, G. A. Processos fonológicos na aquisição da linguagem pela criança. ReVEL, v. 3, n. 5, 2005. ISSN 1678-8931

PEREIRA, T. M. A. 20) A segmentação no processo de aquisição da linguagem escrita. Revista Veredas, v. 15, n. 1, 2016.

SANTOS, R. A aquisição da linguagem. In: FIORIN, J. L. (Org.). Introdução à Linguística I: objetos teóricos. São Paulo: Contexto, 2011, p. 211-227.

SCLIAR-CABRAL, L. Guia Prático de Alfabetização. São Paulo: Contexto, 2003.

SIMÕES, D. Considerações sobre a fala e a escrita: fonologia em nova chave. São Paulo: Parábola Editorial, 2006.

TENANI, L.; REIS, M. C. "E veveram felizes para sempre": análise de grafias nãoconvencionais de vogais pretônicas. Verba Volant, v. 2, $n^{\circ} 1$. Pelotas: Editora e Gráfica Universitária da UFPel, 2011. Dísponível em: $<$ http://letras.ufpel.edu.br/verbavolant/segundo/tenani2.pdf>. Acesso em 29 jul. 2017. 


\section{Apêndice I}

Atividade 1 e 3 (baseadas em palavras isoladas)

\begin{tabular}{|c|c|c|c|}
\hline & Tipo 1 & Tipo 2 & Outros tipos \\
\hline Info. 01 & $\begin{array}{l}\text { Profesora } \\
\text { Caro }\end{array}$ & Tisora & Quarda-chuva \\
\hline Info. 02 & $\begin{array}{l}\text { Prasinha } \\
\text { Tizora } \\
\text { Caxoro } \\
\text { caro }\end{array}$ & $\begin{array}{c}\text { Arvori } \\
\text { jardaXuva } \\
\text { pexe } \\
\text { caxa } \\
\text { cocu } \\
\text { Peão (ativ.3) }\end{array}$ & jardaxuva \\
\hline Info. 03 & $\begin{array}{c}\text { Prasia } \\
\text { caro }\end{array}$ & $\begin{array}{c}\text { Avari } \\
\text { Sou } \\
\text { gataXova } \\
\text { aneo }\end{array}$ & $\begin{array}{c}\text { Prfaro } \\
\text { Avari } \\
\text { Gataxova } \\
\text { copitato } \\
\text { sizzora } \\
\text { caxoto } \\
\text { caxi }\end{array}$ \\
\hline Info. 04 & Prasinha & & $\begin{array}{l}\text { Quarda- chuva } \\
\text { reguua }\end{array}$ \\
\hline Info. 05 & $\begin{array}{c}\text { Prasa } \\
\text { Dizora } \\
\text { cachoro }\end{array}$ & $\begin{array}{c}\text { Compl(u)tador } \\
? \\
\text { dizora }\end{array}$ & $\begin{array}{l}\text { Quagachova } \\
\text { regar }\end{array}$ \\
\hline Info. 06 & $\begin{array}{c}\text { Prasa } \\
\text { Professora } \\
\text { guardaxova } \\
\text { caxoro } \\
\text { caro }\end{array}$ & $\begin{array}{c}\text { Tijora } \\
\text { Regoa } \\
\text { Anehu } \\
\text { Lealau-Piau( } \\
\text { ativ. 3) }\end{array}$ & $\begin{array}{c}\text { dia (sol) } \\
\text { coupitado } \\
\text { tojora }\end{array}$ \\
\hline Info. 07 & $\begin{array}{c}\text { Brasa } \\
\text { Quadadaxuva } \\
\text { coNputadou } \\
\text { caxuro } \\
\text { caro }\end{array}$ & $\begin{array}{c}\text { Sou } \\
\text { ConputadOU } \\
\text { Tisora } \\
\text { CaxUro } \\
\text { Aneu }\end{array}$ & $\begin{array}{c}\text { Nome (professora) } \\
\text { Arver }\end{array}$ \\
\hline Info. 08 & $\begin{array}{l}\text { Prasa } \\
\text { Qoqo } \\
\text { caro }\end{array}$ & $\begin{array}{l}\text { Sou } \\
\text { Copitado } \\
\text { Tizola } \\
\text { rega } \\
\text { ameu } \\
\end{array}$ & $\begin{array}{l}\text { Avre } \\
\text { Caga } \\
\text { caroro }\end{array}$ \\
\hline Info. 09 & $\begin{array}{l}\text { Prasinha } \\
\text { Tizora } \\
\text { Peche } \\
\end{array}$ & $\begin{array}{l}\text { Tizora } \\
\text { peche }\end{array}$ & \\
\hline
\end{tabular}




\begin{tabular}{|c|c|c|c|}
\hline & $\begin{array}{c}\text { Cahorro } \\
\text { Caicha } \\
\text { Cauro }\end{array}$ & & \\
\hline Info. 10 & $\begin{array}{l}\text { Prasa } \\
\text { Tizoura } \\
\text { Peice }\end{array}$ & Cunputador & \\
\hline Info.11 & sonbrinha & $\begin{array}{l}\text { Tisora } \\
\text { caxa }\end{array}$ & contutador \\
\hline Info. 12 & $\begin{array}{c}\text { Prasa } \\
\text { Gardaxouva } \\
\text { amel }\end{array}$ & $\begin{array}{c}\text { Porfesera } \\
\text { Sou } \\
\text { Gardaxouva } \\
\text { Caxa } \\
\end{array}$ & conpitador \\
\hline Info. 13 & $\begin{array}{c}\text { Prasa } \\
\text { Conputador } \\
\text { Disoura }\end{array}$ & & Pixe \\
\hline Info. 14 & Prasa & Professa & \\
\hline Info. 15 & Prasa & $\begin{array}{c}\text { Cocu } \\
\text { guardachova }\end{array}$ & conputador \\
\hline Info. 16 & $\begin{array}{c}\text { Prasinha } \\
\text { Caro } \\
\text { Casoro }\end{array}$ & $\begin{array}{c}\text { sou } \\
\text { Tisora } \\
\text { Pexi } \\
\text { Aneu }\end{array}$ & $\begin{array}{c}\text { Arsori } \\
\text { Copitador } \\
\text { guardajusa }\end{array}$ \\
\hline Info. 17 & Conputador & & \\
\hline Info. 18 & $\begin{array}{c}\text { Sonbrinha } \\
\text { Conputador } \\
\text { Cocô }\end{array}$ & aneu & \\
\hline Info. 19 & & $\begin{array}{l}\text { Ainvori } \\
\text { Tisora } \\
\text { carruu }\end{array}$ & $\begin{array}{c}\text { Pansa } \\
\text { coputadun }\end{array}$ \\
\hline Info. 20 & $\star \star * \star * * * * * *$ & $\star * * * * * * * *$ & $\star * * * * *$ \\
\hline Info. 21 & Prasa & $\begin{array}{c}\text { Tesora } \\
\text { Compurtador }\end{array}$ & \\
\hline Info. 22 & $\begin{array}{c}\text { Caza } \\
\text { Caxoro } \\
\text { caro }\end{array}$ & $\begin{array}{c}\text { Aneu } \\
\text { Cocu } \\
\text { soo }\end{array}$ & \\
\hline Info. 23 & & couputador & \\
\hline $\begin{array}{l}\text { TOTAL: } 141 \\
\text { desvios }\end{array}$ & $\begin{array}{c}54 \text { ocorrências I } \\
38 \%\end{array}$ & $\begin{array}{c}56 \text { ocorrências } \\
40 \%\end{array}$ & $\begin{array}{c}31 \text { ocorrências } \\
22 \%\end{array}$ \\
\hline
\end{tabular}


Atividade 2 (baseada em sentenças)

\begin{tabular}{|c|c|c|c|}
\hline & Tipo 1 & Tipo 2 & Outros tipos \\
\hline Info. 01 & $\begin{array}{l}\text { A tasa crebou } \\
\text { O gelo derete }\end{array}$ & $\begin{array}{l}\text { A tasa ćrebou } \\
\text { A onça é fenroz } \\
\text { O banhelo é } \\
\text { branco }\end{array}$ & \\
\hline Info. 02 & Aonsa é feros & $\begin{array}{l}\text { Atasa que brol } \\
\text { Ogelo derete } \\
\text { Aonsa é feros } \\
\text { Obairo branco }\end{array}$ & \\
\hline Info. 03 & $\begin{array}{c}\text { A tassa } \\
\text { faros }\end{array}$ & & $\begin{array}{c}\text { Cera } \\
\text { O glo T ret } \\
\text { A mosa e faros } \\
\text { O bãoero e bco }\end{array}$ \\
\hline Info. 04 & $\begin{array}{c}\text { A tasa que brol } \\
\text { O gelo de rete } \\
\text { A onsa e feros } \\
\text { O banheiro e } \\
\text { branco }\end{array}$ & $\begin{array}{l}{[\ldots] \text { que brol }} \\
{[\ldots] \text { de rete }}\end{array}$ & \\
\hline Info. 05 & $\begin{array}{c}\text { A tasa[...] } \\
\text { O gelo derete } \\
\text { A orsa é feros }\end{array}$ & $\begin{array}{c}{[\ldots] \text { querou }} \\
\text { O baero é branco }\end{array}$ & \\
\hline Info. 06 & Atasa[...] & $\begin{array}{l}\text { Atasaqebrou } \\
\text { Ogelo de rete } \\
\text { Aousa é feros } \\
\text { Obaeiro e braco }\end{array}$ & \\
\hline Info. 07 & $\begin{array}{c}\text { A tasa gebru } \\
\text { O gelo derete } \\
\text { A onsa[...] }\end{array}$ & $\begin{array}{c}{[\ldots . .] g e b r o u} \\
\text { O baniero é [...] }\end{array}$ & $\begin{array}{l}{[\ldots] \text { Reroes }} \\
{[\ldots] \text { benco }}\end{array}$ \\
\hline Info. 08 & A tasa[...] & $\begin{array}{c}\text { [...] quebro } \\
\text { A oza e felosi } \\
\text { O baelo e }\end{array}$ & $\begin{array}{c}{[\ldots] \text { baoq (branco) }} \\
\text { O glo e ret }\end{array}$ \\
\hline Info. 09 & $\begin{array}{c}\text { A tasa[...] } \\
\text { O gelo derete } \\
\text { A onsa e feros }\end{array}$ & [...] quebrol & \\
\hline Info. 10 & $\begin{array}{c}\text { A tasa[...] } \\
\text { O gelo terrete } \\
\text { A onsa é feros } \\
\text { O banheiro e } \\
\text { branco }\end{array}$ & $\begin{array}{c}{[\ldots] \text { quebrol }} \\
\text { O banheiro e } \\
\text { branco }\end{array}$ & \\
\hline Info. 11 & A onsa é feros & O baieiro[...] & \\
\hline Info. 12 & $\begin{array}{l}\text { Ogelo terete } \\
{[\ldots] \text { e ferois }}\end{array}$ & $\begin{array}{c}\text { Atasa quebro } \\
\text { Ogelo terete } \\
\text { [...] e ferois } \\
\text { obaero[...] }\end{array}$ & $\begin{array}{l}\text { Acosa [...](a onça) } \\
{[\ldots . .] \text { rarco (branco) }}\end{array}$ \\
\hline Info. 13 & A onça e feros & $\begin{array}{l}\text { O gelo de rete } \\
\text { A taça que brou }\end{array}$ & \\
\hline
\end{tabular}




\begin{tabular}{|c|c|c|c|}
\hline Info. 14 & $\begin{array}{c}\text { A onça e ferois } \\
\text { O banheiro e braco }\end{array}$ & $\begin{array}{c}\text { A taça quebrol } \\
\text { A onça e ferois } \\
\text { O banheiro e braco }\end{array}$ & \\
\hline Info.15 & $\begin{array}{c}\text { A tasa }[. . .] \\
\text { A onsa e feros } \\
\text { O banheiro e } \\
\text { branco }\end{array}$ & $\begin{array}{l}{[\ldots] \text { quebrol }} \\
\text { O gelo terete }\end{array}$ & \\
\hline Info. 16 & $\begin{array}{l}\text { O gelo de reti } \\
\text { A ousa é feros }\end{array}$ & $\begin{array}{l}\text { O gelo de reti } \\
\text { O baiero é banco }\end{array}$ & \\
\hline Info. 17 & $\begin{array}{l}\text { O gelo derete } \\
\text { A onsa e efros }\end{array}$ & A taça quebrol & \\
\hline Info. 18 & $\begin{array}{c}\text { A onça eferos } \\
\text { panheiro e pranco } \\
\text { O pan }\end{array}$ & A onça eferos & \\
\hline Info. 19 & $\begin{array}{c}\text { A tasa }[\ldots] \\
\text { O gelo derete }\end{array}$ & $\begin{array}{l}\text { [...] quebrol } \\
\text { O baiero[...] }\end{array}$ & $\begin{array}{c}\text { A gosa ererois } \\
{[\ldots . .] g a c o}\end{array}$ \\
\hline Info. 20 & $* * * * *$ & $\star \star * * * * * * * * * *$ & $\star \star * \star * * * \star * * * *$ \\
\hline Info. 21 & $\begin{array}{c}\text { A taca } \\
\text { O gelo drete } \\
\text { A onsa e feros }\end{array}$ & O gelo drete & O baheiro é branco \\
\hline Info. 22 & $\begin{array}{c}\text { A tasa }[\ldots] \\
\text { A osaeferois }\end{array}$ & $\begin{array}{c}\text { O geodreti } \\
\text { A osaeferois } \\
\text { O baoeroebaoco }\end{array}$ & [...]qdou \\
\hline Info. 23 & A tasa[...] & O gelo terete & A onça é ferroze \\
\hline $\begin{array}{l}109 \text { sentenças } \\
\text { com desvios }\end{array}$ & $\begin{array}{c}48 \text { sentenças com } \\
\text { desvios } \\
44 \%\end{array}$ & $\begin{array}{c}46 \text { sentenças com } \\
\text { desvios } \\
42 \%\end{array}$ & $\begin{array}{c}15 \text { sentenças com } \\
\text { desvios } \\
14 \%\end{array}$ \\
\hline
\end{tabular}


Atividade 4 (produção textual)

\begin{tabular}{|c|c|c|c|}
\hline & Tipo 1 & Tipo 2 & Outros tipos \\
\hline Info. 01 & & $\begin{array}{c}{[\ldots] \text { e seus amigo chegalam }[\ldots]} \\
{[\ldots] \text { A fezta ficou bombamdo[...] }} \\
{[\ldots] \text { teve uma Iteia[...] }}\end{array}$ & \\
\hline Info. 02 & {$[\ldots]$ fin } & $\begin{array}{l}\text { Osaluos es tol nabibioteca[...]Ojuão } \\
\text { foiabriaporta e ossesuamius [...] } \\
\text { ifizerão[...]fin }\end{array}$ & Osaluos \\
\hline Info. 3 & {$[\ldots]$ e ele ficol $[\ldots]$} & $\begin{array}{c}\text { O s lunos i tão[...]Os amigo de goão } \\
\text { chegarão }\end{array}$ & $\begin{array}{c}\text { nalililotala lipis } \\
\text { catai }\end{array}$ \\
\hline Info. 04 & & $\begin{array}{l}\text { As criança es tão na bibilhoteca [...] } \\
\text { lapes[...] } 6 \text { amigo chegou }\end{array}$ & \\
\hline Info. 05 & & $\begin{array}{l}\text { As criança estão[...]Os amigo dele } \\
\text { chegou é os amigo deu um presete. }\end{array}$ & $\begin{array}{c}{[\ldots] \text { na }} \\
\text { bilhoteca }\end{array}$ \\
\hline Info. 06 & & $\begin{array}{c}\text { Osoalunosestaumnabibioteca[...]Ojuã } \\
\text { o tevianivesario é tevibisiceta é } \\
\text { viuma[...] }\end{array}$ & \\
\hline Info. 07 & $\begin{array}{c}{[\ldots] \mathrm{e} \text { ceus }} \\
\text { amigosxegaro[... }\end{array}$ & $\begin{array}{l}\text { Es tãonabribrioteca[...]livos lapess } \\
\text { papeu[...]e ceus amigosxegaro e } \\
\text { bricarão }\end{array}$ & As crião[...] \\
\hline Info. 08 & & {$[\ldots]$ e tiou [...] papeu lapise } & $? ? ?$ \\
\hline Info. 09 & $\begin{array}{c}\text { As crianças[...] } \\
\text { cartases [...] felis }\end{array}$ & {$[\ldots]$ ficol } & \\
\hline Info. 10 & As criasas $[\ldots]$ & $\begin{array}{c}\text { As criasas }[\ldots] \text { bibilhoteca[...] ele } \\
\text { necontrol }[\ldots]\end{array}$ & \\
\hline Info. 11 & & $\begin{array}{c}{[\ldots] \text { biblioteca[...] lapes i tinha um }} \\
\text { presete }\end{array}$ & \\
\hline Info.12 & & $\begin{array}{c}\text { Ozalomo biblioteca livo relogo omino } \\
\text { abril apta viul mino }\end{array}$ & \\
\hline Info.13 & & Os alunos estam na bibilhoteca[...] & 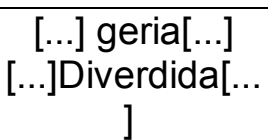 \\
\hline Info. 14 & $\begin{array}{c}\text { [...] seus amigos } \\
\text { xegaram } \\
{[\ldots] \text { tanben[...]e }} \\
\text { os amigos dele } \\
\text { foran enbora }\end{array}$ & [...]a festa acabol[...] & \\
\hline Info. 15 & $\begin{array}{l}\text { [...] e os amigos } \\
\text { do joão falaran }\end{array}$ & $\begin{array}{l}{[. . .] \text { tem relógio e lapes[...] O joão }} \\
\text { abril[...] e o joão ficou enprsonado }\end{array}$ & \\
\hline Info.16 & $\begin{array}{l}{[\ldots] \text { O joão }} \\
\text { xegou } \\
{[\ldots] \text { ele ficou }} \\
\text { felis }\end{array}$ & $\begin{array}{l}\text { Os alunos estau na biblioteca[...] o } \\
\text { joão xegou até a porta[...]depos[...] }\end{array}$ & \\
\hline Info. 17 & & $\begin{array}{l}\text { As crianças estão na bibrioteca [...] o } \\
\text { joão foi abrir a porta e encontrol[...] }\end{array}$ & \\
\hline Info. 18 & $\begin{array}{c}{[\ldots] \text { cartais }} \\
\text { Labis[...]de } \\
\text { comtrole remoto }\end{array}$ & $\begin{array}{c}{[\ldots] \text { cartais }} \\
\text { Labis[...]era uma grade avião }\end{array}$ & \\
\hline
\end{tabular}




\begin{tabular}{|c|c|c|c|}
\hline Info. 19 & & $\begin{array}{c}\text { Os aluno es tam no }[\ldots] \text { o joão gaio } \\
{[\ldots]}\end{array}$ & $\begin{array}{l}\text { Reloje }[\ldots] \text { uma } \\
\text { bisiota }\end{array}$ \\
\hline Info. 20 & $\star \star * \star * \star$ & $\star \star * * \star * \star *$ & $\star * * * * * *$ \\
\hline Info. 21 & & $\begin{array}{l}\text { As criançãs estão na bibrioteca[...] } \\
\text { presetes[...] }\end{array}$ & \\
\hline Info. 22 & O goão[...] & & [...] relo[...]hiou \\
\hline Info. 23 & $\begin{array}{c}{[\ldots] \text { papel }} \\
\text { lapis[...] é o jão }\end{array}$ & $\begin{array}{c}\text { As crinça estão na bliblioteca[...] } \\
\text { os amigos dele chegaro e o jão figou } \\
\text { feliz }\end{array}$ & \\
\hline $\begin{array}{c}47 \\
\text { sentença } \\
\text { s com } \\
\text { desvios }\end{array}$ & $\begin{array}{c}13 \text { sentenças } \\
\text { com desvios } \\
28 \%\end{array}$ & $\begin{array}{c}24 \text { sentenças com desvios } \\
51 \%\end{array}$ & $\begin{array}{c}10 \text { sentenças } \\
\text { com desvios } \\
21 \%\end{array}$ \\
\hline
\end{tabular}

Artigo recebido em 12/11/2017

Artigo aceito em 07/05/2018 